\title{
PV self-consumption optimization with storage and Active DSM for the residential sector
}

\author{
M. Castillo-Cagigal ${ }^{\text {a,b,* }}$, E. Caamaño-Martín ${ }^{\text {b }}$, E. Matallanas ${ }^{a, b}$, D. Masa-Bote ${ }^{b}$, \\ A. Gutiérrez ${ }^{\text {a }}$, F. Monasterio-Huelin ${ }^{a}$, J. Jiménez-Leube ${ }^{a}$ \\ "ETSI Telecomunicación, Universidad Politécnica de Madrid, Av. Complutense 30, 28040 Madrid, Spain \\ ${ }^{\mathrm{b}}$ Instituto de Energía Solar, Universidad Politécnica de Madrid, Av. Complutense 30, 28040 Madrid, Spain
}

\begin{abstract}
With the rising prices of the retail electricity and the decreasing cost of the PV technology, grid parity with commercial electricity will soon become a reality in Europe. This fact, together with less attractive PV feed-in-tariffs in the near future and incentives to promote self-consumption suggest, that new operation modes for the PV Distributed Generation should be explored; differently from the traditional approach which is only based on maximizing the exported electricity to the grid. The smart metering is experiencing a growth in Europe and the United States but the possibilities of its use are still uncertain, in our system we propose their use to manage the storage and to allow the user to know their electrical power and energy balances. The ADSM has many benefits studied previously but also it has important challenges, in this paper we can observe and ADSM implementation example where we propose a solution to these challenges. In this paper we study the effects of the Active Demand-Side Management (ADSM) and storage systems in the amount of consumed local electrical energy. It has been developed on a prototype of a self-sufficient solar house called "MagicBox" equipped with grid connection, PV generation, lead-acid batteries, controllable appliances and smart metering. We carried out simulations for long-time experiments (yearly studies) and real measures for short and mid-time experiments (daily and weekly studies). Results show the relationship between the electricity flows and the storage capacity, which is not linear and becomes an important design criterion.
\end{abstract}

Keywords: Active Demand-Side Management; Self-consumption; PV systems; Battery storage; Distributed energy; Smart metering

\section{Introduction}

As expounded in the work of Bhandari and Stadler (2009), if a household uses his own PV generated energy, it will save the money that would have otherwise paid as retail price. In this case, grid parity is forecast for the 2013-2014 in some European countries. If the household intends to sell the electricity to the grid, it will receive the wholesale price as revenue and in this case grid parity is estimated in 2023-2024. Therefore, by increasing the selfconsumed local generated energy, the grid parity could be achieved earlier. This fact, together with the less attractive PV feed-in-tariffs in the near future and the incentives to promote self-consumption (existing in Germany since 2009 and currently under discussion in Spain), suggests that new operation modes for PV Distributed Generation should be explored; differently from the traditional approach which is only based on maximizing the electricity exported to the grid. 
There is no commonly accepted definition for the term Demand-Side Management (DSM). It is defined here as actions that influence the way consumers use electricity in order to achieve savings and higher efficiency in energy use, has been identified as one of the main strategies to be promoted in order to guarantee security of supply in the European Union (European Commission, 2002). The use of DSM brings many benefits, such as: To reduce the generation margin (decreasing the need for backup generation), to improve transmission-distribution grid investment (adjusting the size of the lines to local demand), and operation efficiency (decreasing the need for energy transport). However the use of DSM also has to face different challenges: Lack of ICT infrastructure because the absence of monitoring, communication and control systems in the grid, lack of understanding of the benefits and the difficulty to evaluate them, increase the complexity of the system, etc. (Strbac, 2008).

The use of DSM may also be used to mitigate the variations in production of renewable energy, being able to make greater use of these technologies (Moura et al., 2010). It can reduce building peak demand, decreasing the transport losses through the grid and the pollutant emissions (Spiegel et al., 1997). The combination of DSM with an automatic control of the household demand leads to a new concept called "Active Demand-Side Management" (ADSM). Moreover, in this paper, ADSM is implemented together new-generation PV hybrid technology (grid connected-type inverters with small-scale electricity storage and an automatic control of the grid interface) from which not only PV systems operators can profit, but also other consumers connected to the same grid (through cooperative strategies) and the grid itself (if the PV systems respond to signals coming from the distribution system operator). Residential consumers could be the first to benefit from ADSM strategies, provided that technologies exist that facilitate (automate) the task without compromising the users comfort needs and preferences. Moreover, the residential sector can be a potential customer for the ADSM technology, because it can be combined with additional comfort and security functions, improving the demand response and reducing the environmental impacts (Papagiannis et al., 2008) and offering the user to know its electrical consumption. Although the ADSM does not reduce directly the amount of demanded energy, the work presented by Wood and Newborough (2003) concludes that by applying consumption information feedback to the users the rates of energy consumption at home can be reduced. Currently, ADSM is increasingly viable by means of highly efficient electrical appliances that can be remotely controlled. However, to perform a true ADSM several challenges must be faced up:

- From a PV engineering perspective, supervision and management are necessary to know in real-time the status of the PV system components, as well as to forecast the expected generation in a short time scale (for example, on a $24-h$ basis).
- From a control engineering perspective, loads management should be able to deal with many parameters and variables influencing the consumption pattern (related to the user preferences and electrical appliances). In addition, it should also consider information coming from the local sources (PV and storage) and the grid (price signals, remote commands, etc.).

Other technologies more mature than the ADSM and with a greater energy management ability are the electrical energy storage systems. But the use of storage in grid-connected applications is not very common, unless we consider the pumping station to storage electrical energy from the grid in the overproduction hours (Hadjipaschalis et al., 2009). The main reasons of storage absence in the grid is its expensive cost and the generation control possibilities of the classical power stations, making not profitable the implementation of new storage technologies on a large scale. However, the currently technological and energy situation encourages the investment in storage systems, mainly because of the increase of the renewable energies presence in the energy-mix (Foidart et al., 2010) and the strong hourly mismatch between the demand and generation pattern (Lior, 1997; Wagner, 1997). An example of using storage systems with renewable energy is to improve the grid in-feed accuracy (Koeppel and Korpas, 2008). The work presented by Denholm and Margolis (2007) concludes that the use of load shifting and electrical energy storage is needed to achieve PV high penetration levels.

There are considerable researches on the use of ADSM and electrical energy storage or a combination of both. In the work presented by Mulder et al. (2010), measurement data of seven households in Belgium have been used to acquire relationships to dimension storage packages for grid connected PV panel installations. A methodology for the evaluation of PV array orientation, ADSM and storage to improve load matching has been presented in Widén et al. (2009). The method was applied in simulations to high-latitude data from detached houses and apartments in Sweden to observe their impact.

In this paper, we propose the use of a lead-acid battery storage system and ADSM in small consumer installations, specifically in the residential sector, in order to increase the use of local PV electricity. Simulations and real experiments have been carried out for the climatology and typical Spanish residential consumption. To evaluate the self-consumption an evaluation methodology has been developed, it is focused in the definition of the self-consumption factor similar to the solar fraction defined by Widén et al. (2009) but including the stored electrical solar energy. The results show how different energy variables evolve for different battery capacities and with the presence or absence of ADSM. Another important development in this paper is the study of batteries float charge consumption effect in the energy balance of the system.

The study presented in this paper is done over an electric system based on hybrid PV generation technology. It has 


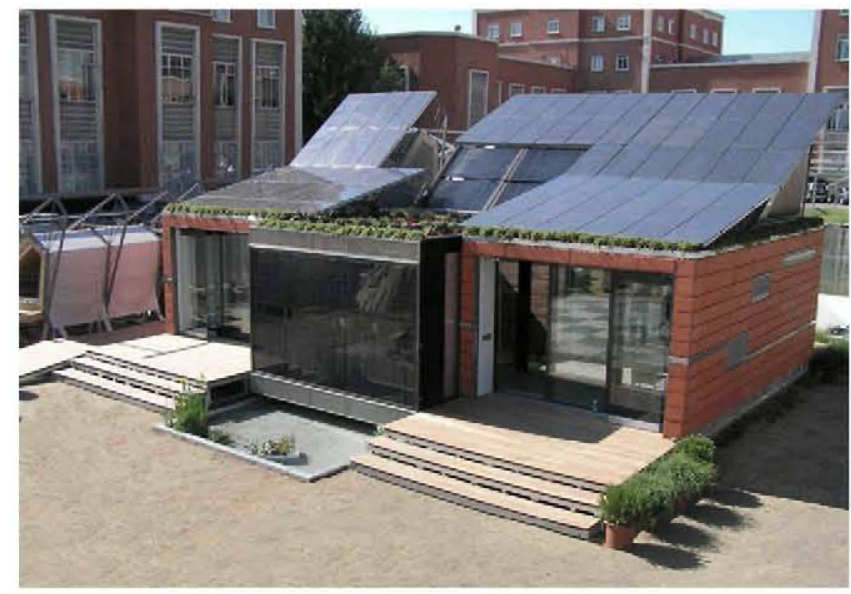

Fig. 1. Frontal view of MagicBox.

been developed on a prototype of self-sufficient solar house called "MagicBox" (see Fig. 1). By developing models based on "MagicBox", simulations has been carried out. By using the simulation results, real experiments have been done with the more significant battery capacities. The aim of this study is not only to show the relation of the local energy balance (focused in self-consumption) between different system's parameters, but also an example of a functioning system that responds to the challenges of ADSM.

The remainder of this paper is as follows. Section 2 describes the electrical energy system used in our experiments, including the battery controller and the floating state losses. In Section 3, the analysis method which evaluates the system is defined as well as the data used in the simulations. Section 4 presents results in simulations; they are explained and discussed in order to improve their understanding. Section 5 shows real experiments carried out in a real house. Finally, Section 6 concludes this paper.

\section{Electric system}

The system integrates PV hybrid generation, loads control technologies in order to displace the consumers load curve in response to local conditions and a battery controller. The control system (ADSM and battery controller) receives information about the local conditions and executes different actions in order to maximize the self-consumption, as it is explained in the next sections. This hybrid generation is composed of a PV generator, a storage system, a grid connection and different loads representing the user demand. The electricity exchange between the different components marks the energy behavior of the system. Fig. 2 shows the system topology, where the arrows mark the positive direction.

The system is equipped with digital electric meters also called "smart meters", in order to measure the power flows in the house. These equipments provide many possibilities of remote monitoring and communication. With the smart meters more complex billing calculations and load and storage management can be implemented. Moreover, they

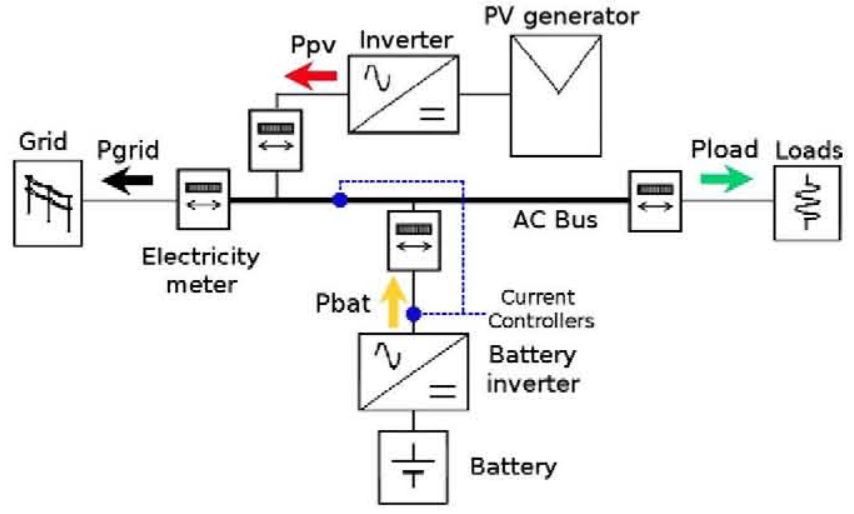

Fig. 2. Topology of the AC system installed in the solar house. The arrows mark the positive direction of the power flows in our equations.

can provide customers information from the grid. It is expected that their penetration would grow during the next years in Europe and the United States (Beyea, 2010). The meters measure the power flows in real time and the energy which crosses them in both ways for a time period. They are connected to the control system via a RS-485 bus. We use them to monitor the electric information in four points in the house (see Fig. 2). Therefore, the main power variables used in our system are measured to control the system operation and to provide information about the energy operation to the user (see Section 3).

\subsection{PV generators}

The concept of self-consumption only has sense if local generation is available. This paper is focused in the residential sector, therefore PV electricity has been used as local generator. PV technology has the best characteristics to be integrated in buildings, like noiseless generation, no pollution, scalability, etc. The presence of PV generation is increasing worldwide, achieving $9.8 \mathrm{GW}$ in Germany and $3.5 \mathrm{GW}$ in Spain of installed power at the end of 2009 (Programe, 2010). Furthermore, PV grid-connected systems offer nowadays solutions to improve grid supply quality and provide grid services, as participation in grid-supporting or grid-forming modes of operation (Caamaño-Martín et al., 2008).

The implemented PV installation consists of five independent monocrystalline PV fields with $5.55 \mathrm{kWp}$ of total generation. The fields are distributed in different southoriented surfaces. Each surface has a different tilt with: $1.45 \mathrm{kWp}$ for $12^{\circ}, 2.7 \mathrm{kWp}$ for $25^{\circ}, 0.8 \mathrm{kWp}$ for $39^{\circ}$ and $0.6 \mathrm{kWp}$ for $90^{\circ}$. Therefore, the PV generation is set in order to achieve different balances along the year. Each PV field has an associated string-type inverter. Therefore, the PV AC power is supplied to the AC bus, as is shown in Fig. 2. Notice that the objective of this paper is not the study of the PV installation quality but the self-consumption. Therefore parameters of the installation such as the MPPT and inverter efficiency are not addressed. 


\subsection{Storage system and battery controller}

The use of storage systems are currently not very extended in the residential sector. This situation is changing because of the electricity management possibilities for consumers and small power producers. Thus, battery energy storage systems are likely to have a significant impact in the small-scale integration of renewable energy sources into commercial and residential sectors (Nair and Garimella, 2010). Moreover, several storage technologies are in use today in multiple applications, while others are still under research and development (Hadjipaschalis et al., 2009; Wagner, 1997). Therefore, storage cost reduction and new applications such as the electric vehicles are expected in the near future. With the aim of studying the effects of these growing technologies, storage capacity has been included in our system. The house is equipped with a lead-acid battery bank. The battery bank is divided in 24 cells, each cell has a capacity of $750 \mathrm{Ah}\left(C_{10}{ }^{1}\right)$ and a voltage of $2 \mathrm{~V}$. Therefore, the total battery bank voltage is $48 \mathrm{~V}$ with a capacity around $36 \mathrm{kWh}$. This capacity value is quite high for a simple house, whose daily consumption is around $12 \mathrm{kWh}$. For this reason, we do not use the $100 \%$ of the total capacity as will be explained in Section 3.

Because the battery operates with DC current and all energy exchanges are produced through the $\mathrm{AC}$ bus (even the PV energy excess storage), the system is equipped with a battery inverter. This inverter does not only implement the current conversion, but allows controlling the power flows in the house. This control is implemented through two stream controllers, situated in the blue ${ }^{2}$ points marked in Fig. 2. These controllers limit the current which flows in these lines.

Thanks to the stream controllers and the smart meters, we have developed a high-level software battery controller. The main objective of the battery controller is to maximize self-consumption by focusing on the following restriction: there are no energy exchanges between the storage system and the grid. It means that the battery can only be charged with the PV energy excess and can only be discharged to the loads. Furthermore, the battery controller preserves the battery life-time by avoiding overcharge and deep discharge situations.

The battery controller has been implemented with a software controller which monitors the power flows and some storage system variables, and actuates over the stream controllers. By using this information, the software controller implements the aforementioned operation. The main storage system variable is the battery State of Charge (SoC), used to preserve the battery life-time. Whenever SoC $\geqslant 95 \%$, no more energy is allowed to be stored in the battery; it supplies the loads but the PV energy excess feeds the grid, preserving the battery of overcharge.

\footnotetext{
${ }^{1}$ Capacity for $10 \mathrm{~h}$ discharge cycles.

${ }^{2}$ For interpretation of color in Fig. 2, the reader is referred to the web version of this article.
}

Whereas SoC $\leqslant 20 \%$, no more energy is taken from the battery; it stores the PV generation excess, but the consumption excess is supplied by the grid, preserving the battery of deep discharge. For the midcharge $(20 \leqslant$ SoC $\leqslant 95)$ the controller performs the self-consumption maximization by no exchanging energy with the grid. Eq. (1) describes the house energy behavior for the midcharge situation:

$$
\begin{aligned}
& P_{\text {Grid }}=0 \\
& \text { If } P_{\text {Load }} \leqslant P_{P V} \rightarrow P_{B a t}=P_{\text {Load }}-P_{P V} ; P_{P V, \text { load }}=P_{\text {Load }} \\
& \text { If } P_{\text {Load }}>P_{P V} \rightarrow P_{\text {Bat }}=P_{\text {Load }}-P_{P V} ; P_{P V, \text { load }}=P_{P V}
\end{aligned}
$$

where $P_{\text {Grid }}$ is the power exchanged with the grid, $P_{\text {Load }}$ is the power consumed by the loads, $P_{P V}$ is the PV power, $P_{B a t}$ is the power exchanged with the battery and $P_{P V \text {,load }}$ is the PV power that fed the loads.

Electrical energy storage has different energy losses associated, which are the main technical disadvantages of these technologies. These losses are normally related to the efficiency, as the electro-chemical conversion in the battery cells and the inverter efficiency in the DC/AC conversion (Salkind et al., 2001). The battery efficiency losses are studied in this paper. Moreover, we include the battery float charge losses, which are due to the energy that is used to maintain the battery charged when it is full charged ( $\mathrm{SoC} \approx 100 \%$ ). This amount of energy is not useful for the global energy system but is needed to keep a battery storage system in proper operation. Typically, these losses are not taken into account because they are not significant for stand-alone systems and for high storage capacity systems. However, on a grid-connected house equipped with low storage capacity, the float charge losses represent an important amount of energy (see Section 4). Therefore, a battery float charge consumption of $100 \mathrm{~W}$ has been inserted in our studies, which is a typical value of this consumption. The internal battery energy flows and the electric energy exchange with the $\mathrm{AC}$ bus are summarized in Fig. 3 , where $E_{B a t, E}$ is the energy exported from the $\mathrm{AC}$ bus to the battery storage system, $E_{B a t, I}$ is the energy imported from the battery storage system to the AC bus, $E_{F l o a t}$ is the energy consumed by the battery float charge, $E_{B a t, s t r}$ is the stored energy into the battery, $\rho_{i}$ is the input efficiency, $\rho_{o}$ is the output efficiency and $E_{\text {Charged }}$ and $E_{\text {Discharged }}$ are the useful energy charged and discharged from the battery respectively.

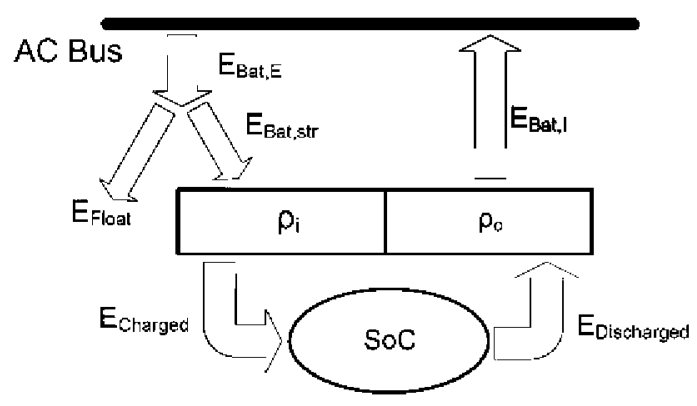

Fig. 3. Battery energy flows schematic. 


\subsection{Demand}

Magicbox includes typical electrical appliances of a highly electrified house: washing machine, dryer, dishwasher, refrigerator, cooking appliances, lighting, computers and entertainment appliances. The washing appliances are integrated in a domotic system, which allows the appliances to be monitored and controlled by a remote system. Thanks to these controllable appliances, an ADSM system has been developed in order to increase the self-consumption factor of the house. The other appliances can be monitored but not controlled. Some of them involve an instantaneous use because of their operation mode (e.g. lights, TVs, computers, etc.). This instantaneous use is indicated by the user in real time as in a common dwelling, and its consumption pattern represents the user's habits. For this reason we have defined two types of electrical demand:

- Deferrable, as the energy demand that can be displaced along the day. In this case, the user set up time limits within which the task has to be carried out. E.g.: to run the washing machine between 10:00 $\mathrm{h}$ and 16:00 h.

- Non-deferrable, as the energy demand that is not controllable. It represents the instantaneous consumption, like lights, TVs, etc. or the continuous consumption, like the fridge, and control computers.

\section{Analysis method}

As aforementioned, the aim of this work is to evaluate the capacity of storage and ADSM to increase the self-consumed electricity in the residential sector. Both, the ADSM system and the battery controller are set in order to maximize the use of the PV local generation. Simulated and real experiments have been carried out following an analysis methodology. In this section the rules applied to the different components and the evaluation methods are explained.

\subsection{Evaluation equations}

In order to evaluate the electrical energy behavior of the system, we have measured the system energy balances and defined the self-consumption factor. The energy balances are the integral of the power flows during a time period (e.g.: $E_{P V \text { load }}$ is the energy which comes from the PV generation and is directly consumed by the loads). The time period has been fixed to a day. The following equations are applied to the electrical energy balances.

For the total PV electrical energy:

$E_{P V}=E_{P V, l o a d}+E_{P V, b a t}+E_{P V, \text { grid }}$

where $E_{P V}$ is the total PV electrical energy, $E_{P V \text {,load }}$ is the $\mathrm{PV}$ energy that fed the loads, $E_{P V, \text { bat }}$ is the stored energy in the battery and $E_{P V \text {,grid }}$ is the PV energy that is exported to the grid.
For the electrical demand:

$E_{\text {Load }}=E_{P V, \text { load }}+E_{\text {Bat }, \text { load }}+E_{\text {Grid,load }}$

where $E_{\text {Load }}$ is the total energy consumed by the loads, $E_{\text {Bat,load }}$ is the energy imported form the battery to the loads and $E_{\text {Grid,load }}$ is the electrical energy taken from the grid to the load.

For the electrical energy managed in the battery:

$E_{B a t, E}=E_{B a t, I}+E_{S o C}-E_{S o C, 0}+L_{B a t}$

where $E_{S o C}$ is the SoC at the end of the time period, $E_{S o C, 0}$ is the SoC at the beginning of the period and $L_{B a t}$ is the total energy lost by the battery storage system.

The storage energy losses have been studied in this paper. These losses have been divided in two main groups, the losses caused by the battery float charge and the losses with regard to the efficiency. Eq. 5 represents the global losses:

$L_{\text {Bat }}=E_{\text {Bat }, E}-E_{\text {Bat }, I}-\Delta E_{\text {SoC }}=L_{\text {Bat }, \text { eff }}+E_{\text {Float }}$

where $L_{B a t, e f f}$ are the storage efficiency losses and $\Delta E_{S o C}$ is the battery charge difference in $\mathrm{kWh}$ in the analyzed period $\left(\Delta E_{S o C}=E_{S o C}-E_{S o C, 0}\right)$.

The losses with regard to the efficiency represent the energy lost because of the inverter efficiency and the electro-chemical battery efficiency. They are involved in the used technology and their values increase as the storage use grows. A schematic view of these losses is represented in Fig. 3 and defined by Eq. (6):

$L_{B a t, e f f}=\left(1-\rho_{i}\right) E_{B a t, s t r}+\frac{\left(1-\rho_{o}\right)}{\rho_{o}} E_{B a t, I}$

Eq. (7) represents the total energy given to the battery storage system and the two main energy ways taken into account. These energy flows in the battery storage system are represented in Fig. 3.

$E_{\text {Bat }, E}=E_{\text {Bat,str }}+E_{\text {Float }} \rightarrow E_{\text {Float }}=E_{\text {Bat } E}-E_{\text {Bat }, s t r}$

We can calculate $E_{B a t, s t r}$ as:

$\Delta E_{\text {SoC }}=\rho_{i} E_{\text {Bat }, s t r}-\frac{E_{\text {Bat }, I}}{\rho_{o}} \rightarrow E_{\text {Bat }, s t r}=\frac{\Delta E_{S o C}}{\rho_{i}}+\frac{E_{\text {Bat }, I}}{\rho_{i} \rho_{o}}$

Recall that in our system there is not energy exchange between the grid and the battery storage system. Therefore the system responds to the next equalities:

$$
\begin{aligned}
& E_{B a t, E}=E_{P V, \text { bat }} \\
& E_{\text {Bat }, I}=E_{B a t, \text { load }} \\
& E_{\text {Grid, }, E}=E_{P V^{\prime}, \text { grid }} \\
& E_{\text {Grid }, I}=E_{\text {Grid,load }}
\end{aligned}
$$

where $E_{\text {Grid,I }}$ is the energy imported form the grid to the AC bus and $E_{\text {Grid,E }}$ is the energy exported from the AC bus to the grid.

Once we have defined the energy balances in the house, we develop the self-consumption factor previously defined in Castillo-Cagigal et al. (2011). The self-consumption represents the electrical energy consumed by the loads 
Table 1

Typical daily consumption in "MagicBox".

\begin{tabular}{lll}
\hline Appliance & $\begin{array}{l}\text { Consumption } \\
\text { (W h/day) }\end{array}$ & $\begin{array}{l}\text { Share } \\
\text { of total (\%) }\end{array}$ \\
\hline $\begin{array}{l}\text { Deferrable } \\
\text { Washing machine }\end{array}$ & 785.92 & 6.95 \\
Dryer & 962.6 & 8.5 \\
Dishwasher & 693.6 & 6.13 \\
Total (deferrable) & 2442.12 & 21.6 \\
Non-deferrable & & \\
Lights & 1302 & 11.5 \\
Cook & 1255.15 & 11.1 \\
Fridge & 616.73 & 5.4 \\
Computers and entertainment appliances & 5694 & 50.03 \\
$\quad$ TV, DVD, etc.) & & \\
Total (non-deferrable) & 8867.88 & 78.4 \\
Total & 11,310 & 100 \\
\hline
\end{tabular}

which is supplied by the local generation sources. Therefore, the self-consumption factor $(\xi)$ is represented by:

$\xi=\frac{E_{P V, \text { load }}+E_{\text {Bat, load }}}{E_{\text {Load }}}$

It should be noted that $\xi$ can be used in different timeframes. Moreover, because $\xi$ is normalized by the loads demand $(\xi \in[0,1])$, it allows to compare systems with different sizes and loads. $\xi=0$ would be the case of a building with no local generation available, and $\xi=1$ when all the energy is locally supplied.

\section{2. $P V$ generation}

The PV generation system is equipped with a $24 \mathrm{~h}$ forecast program (Masa-Bote and Caamaño-Martín, 2010) based on meteorological data from the State Meteorological Agency. With this information, the ADSM system finds the best operation time to maximize the self-consumption factor $(\xi)$. Both, the real PV generation and the PV forecast have been measured during a year with hourly accuracy, creating the PV generation database of our system. This information is necessary to assess the PV generators and to simulate our system operation with real values.

\subsection{The demand and its management}

The electrical consumption pattern is based on measurements carried out in the "MagicBox". We have measured the deferrable energy based on the washing machine, dryer and dishwasher. The non-deferrable demand has been measured by connecting the fridge, computers and entertainment appliances during the day, the cooking appliances at midday and the lighting at the evening. Table 1 shows the house's daily consumption divided into both types of demand. Notice that the deferrable appliances represent the $21.6 \%$ of the total consumption. On the other hand, the main consumption comes from the computers and entertainment appliances typical of dwellings with high technology penetration. Moreover, notice that heating and cooling electric systems have not been included.

The demand pattern depends on different parameters, such as attitudinal factors, family and socio-economic groups, household type, etc. In this paper, we have defined a daily consumption pattern typical of a Spanish weekly day (REE, 1998), with the main demand at the evening, where there are more time to set up the washing appliances, and at midday because of the cooking. We have established this pattern for the year with no seasonal and weekend differences.

Thanks to the existence of the deferrable demand we have developed an ADSM control system detailed in Castillo-Cagigal et al. (2011). The main objective of the ADSM system is to displace the deferrable consumption in order to maximize the self-consumption factor. The daily PV generation forecast and the appliance consumption information are used. By combining both patterns, the ADSM system finds a daily task schedule which optimizes the self-consumption. Therefore in computer simulations and in real experiments we have considered two possible situations: with and without ADSM. Without ADSM involves the use of a fixed typical Spanish demand pattern, in which the deferrable consumption is allocated at the evening hours regardless of the solar resource. With ADSM the controller allocates the deferrable demand along the day using preference time intervals defined by the user and taking into account the solar resource (Castillo-Cagigal et al., 2011). Non-deferrable demand is common to both situations.

\subsection{Storage system}

The real lead-acid battery storage system has a fixed physical capacity, which is not possible to modify dynamically. Thanks to the use of the software battery controller, the useful energy storage capacity and the discharge limit can be modified in real time. In this paper, we study the electric behavior of the house by working with different battery storage capacities managed by the software battery controller.

\section{Self-consumption evolution}

The battery capacity has been normalized to the daily energy consumption in order to represent the capacity in days of autonomy. This capacity representation is typically used in stand-alone systems and allows comparing the results with different consumption patterns.

$C_{n}=\frac{C_{\text {Bat }}(\mathrm{kW} \mathrm{h})}{E_{\text {Load }}(\mathrm{kW} \mathrm{h})}$

where $C_{n}$ is the normalized capacity and $C_{b a t}$ is the absolute battery capacity.

Generally, as the storage system capacity grows the system independence from the grid increases. The energy variables analyzed are $E_{G r i d, I}, E_{G r i d, E}, E_{B a t, E}$ and $E_{B a t, I}$ defined 
in Eqs. (2)-(4) and (9). The first part of the study has implemented yearly simulations using a model of "MagicBox". The energy values are the total annual energy amount and the self-consumption factor is the annual daily average. In Fig. 4a and $b$ the evolution of these variables can be observed with regard to the normalized capacity without and with ADSM respectively. Each point is the result of a yearly simulation for the capacity value represented in the abscissa axis. We observe that the influence of a storage system in the house energy behavior is not linear with its capacity. For low capacity levels, the energy balances varies severely. Close to one day of autonomy $\left(C_{n} \approx 1\right)$ this tendency changes and begins to soften. For high capacity levels, the functions saturate and achieve a plateau value marked by the yearly generation and demand. Notice that on $C_{n}=0$ there is an abrupt variation for the $E_{\text {Grid,E }}$ and $E_{B a t, E}$ variables because the battery float charge consumption. The float charge is activated when the battery is fullcharged ( $\mathrm{SoC} \approx 100 \%$ ) and it is used to preserve the battery stored energy. This consumed energy is not useful and increases as the battery is more time in the full-charge state, a common situation for low capacity levels. Therefore, this abrupt variation on $C_{n}=0$ represents the energy cost which belongs to the float charge power of the battery storage system. Moreover, $E_{B a t, I}$ represents the energy which is supplied from the battery to the loads. It should be similar to $E_{B a t, E}$, but the battery losses cause the difference between them.
Fig. $4 \mathrm{c}$ and $\mathrm{d}$ represents the losses with regard to the normalized capacity. Again, this relation is not linear and need to be taken into account in order to design the system. The $E_{\text {Float }}$ is the most representative loss for low capacity levels, because the battery storage system is most of the time in the full-charge situation. The $L_{B a t, \text { eff }}$ draws an evolution similar to $E_{B a t, E}$ and $E_{B a t, I}$ because of the efficiency losses are proportional to the battery storage system use (see Eq. (6)). Finally, $L_{B a t}$ is the addition of both losses, which is attenuated with the use of ADSM because of the reduction of battery use.

The self-consumption factor resumes the system energy behavior by applying Eq. (10). In Fig. 5a the evolution of self-consumption with regard to the normalized capacity, with and without ADSM, can be observed $\left(\xi\left(C_{n}\right)\right)$. In accordance with the evaluation equations (see Section 3 ), the evolution of the self-consumption is inversely proportional to the consumed energy from the grid. This fact can be observed by comparing Fig. 5a with the $E_{G r i d, I}$ in Fig. $4 a$ and $b$.

The use of ADSM modifies considerably the house energy behavior. Generally, the ADSM increases the $E_{P V}$, load and therefore the self-consumption factor. But this increase is not constant for all battery capacities. In Fig. 5b the improvement of $\xi$ produced by the use of ADSM in relation with the capacity can be observed. This improvement is represented in absolute value and relative to the results without the ADSM. Notice that for low
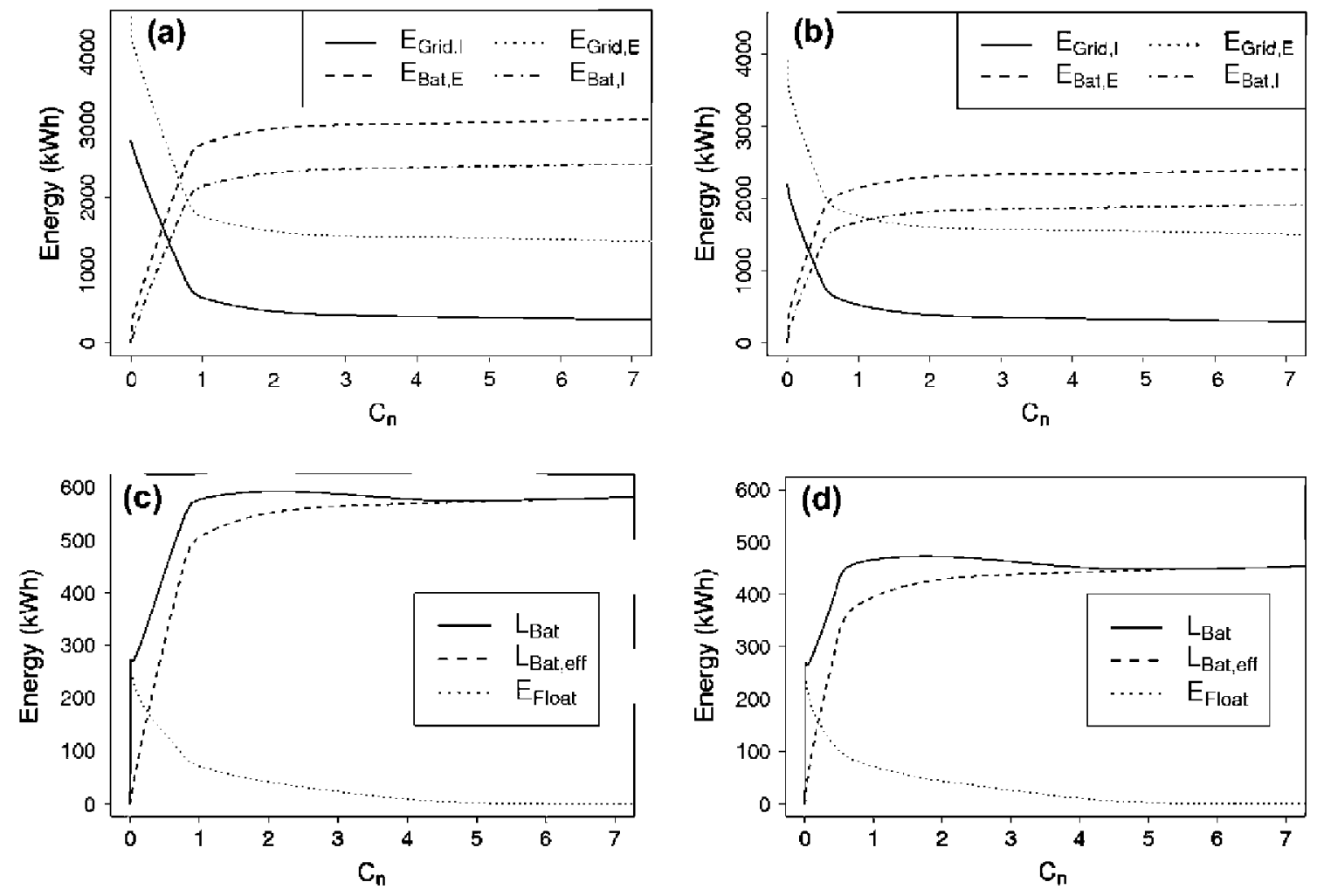

Fig. 4. Electrical energy flows and battery storage system losses for the simulated annual experiments: (a) energy variables without ADSM, (b) energy variables with ADSM, (c) battery losses without ADSM and (d) battery losses with ADSM. 

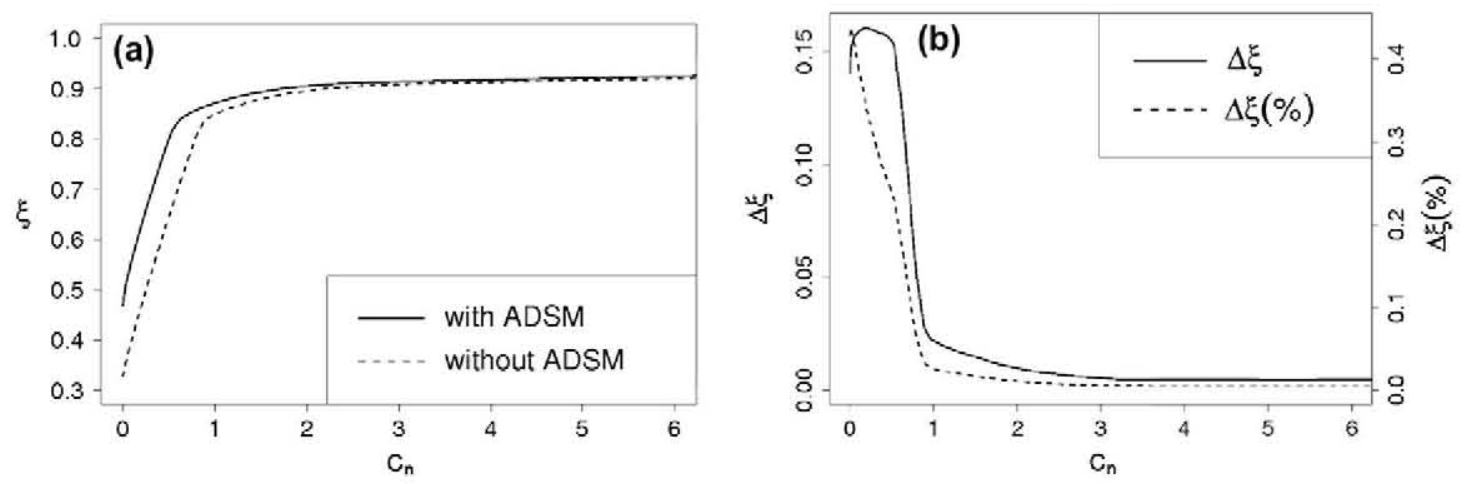

Fig. 5. Self-consumption factor relation with the storage capacity: (a) absolute value and (b) increase because the use of ADSM system.

capacity levels the increase of $\xi$ achieves his maximum. When the system capacity is higher than one day of autonomy the effects of ADSM are not significant. Therefore, when the storage system has enough capacity to manage this amount of energy, the demand time location is not the main parameter for the house energy behavior. In this case, the main parameter which affects to the energy balance is the PV daily generation.

An important point in the $\xi\left(C_{n}\right)$ function is at $C_{n}=0$, it means no storage system. For this situation self-consumption without ADSM represents the $32.7 \%$ of the total demand and $46.8 \%$ with ADSM. In order to achieve $46.8 \%$ of self-consumed energy, a 0.2 days of autonomy battery storage system is needed without ADSM system. It involves that in this point the use of ADSM is equivalent to a small size storage system.

\section{Real experiments}

Analyzing the simulated results, the effects of ADSM and capacity variations have been observed. With this information, we have carried out four real experiments in the solar house "MagicBox". There are secondary effects which have not been taken into account in the simulations as communication delays, smart meter consumption, etc., that do not affect to the tendency previously observed. We have measured the power flows in the house during a week for each operation conditions, modifying the battery capacity and activating or not the ADSM.

Firstly, we have studied the energy behavior without storage, fixing the battery capacity to $0 \mathrm{kWh}$. In this situation the effects of the ADSM can be easily observed, increasing considerably the self-consumption factor. In order to make the representation easier, we have selected two days of each measured week with and without ADSM. In Fig. 6 the power flows for a day without and with ADSM are shown.

The ADSM system displaces part of the demand from the evening hours to the maximum generation hours. There is an important reduction of demanded power from the grid to the detriment of the exported PV electricity. This effect happens throughout the week, increasing the selfconsumption factor average. Table 2 shows the energy which has been used in the house during the experiments. Recall that there is not storage and thus not battery electricity exchange. In these experiments, the use of ADSM has increased $\xi$ in $26 \%$ during a week.

The next experiments have been carried out with a battery capacity of $5.4 \mathrm{kWh}$. The presence of storage makes possible the local generated energy management, thus it increases the house self-consumption. Fig. 7 shows the electricity flows during two example days with and without ADSM. Again, the ADSM displaces the deferrable loads from the evening hours to the maximum generation hours. The battery has enough capacity to supply the local con-
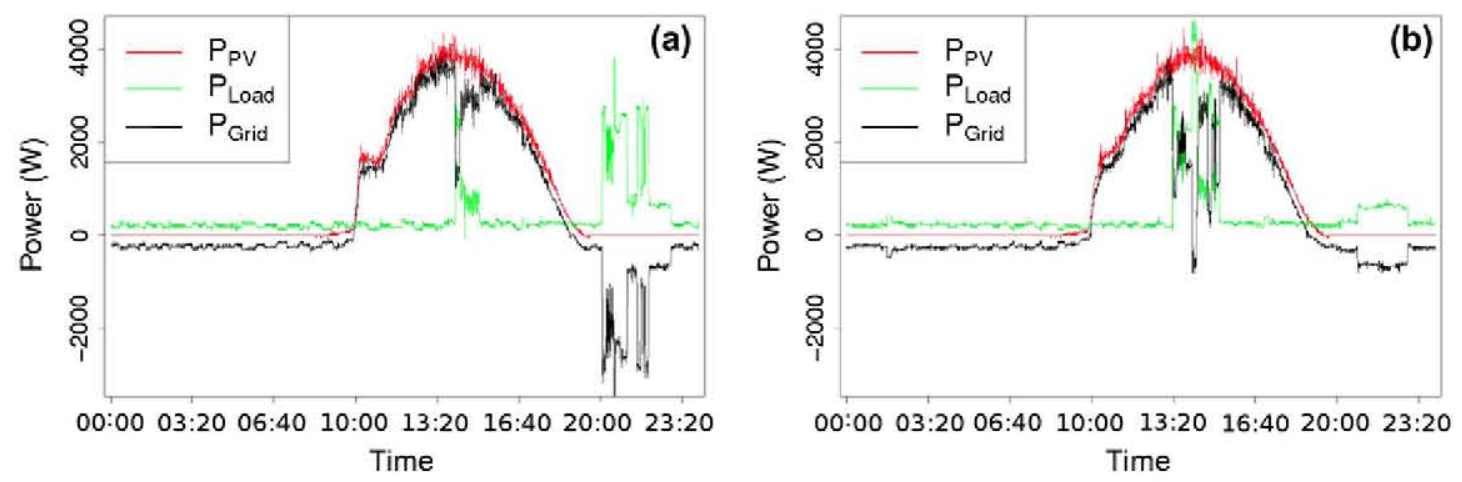

Fig. 6. Electrical energy flows during real example days without storage carried out in MagicBox: (a) without ADSM and (b) with ADSM. 
Table 2

Electrical energy flows during real example days and measured weeks without storage carried out in MagicBox.

\begin{tabular}{|c|c|c|c|c|}
\hline Parameter & $\begin{array}{l}\text { Day without } \\
\text { ADSM }\end{array}$ & $\begin{array}{l}\text { Day with } \\
\text { ADSM }\end{array}$ & $\begin{array}{l}\text { Week without } \\
\text { ADSM }\end{array}$ & $\begin{array}{l}\text { Week with } \\
\text { ADSM }\end{array}$ \\
\hline$E_{P V}(\mathrm{Wh})$ & 23,501 & 23,760 & 159,332 & 165,222 \\
\hline$E_{P V, \text { load }}(\mathrm{Wh})$ & 3427 & 6329 & 23,151 & 43,799 \\
\hline$E_{\text {Grid,E }}(\mathrm{W} \mathrm{h})$ & 20,074 & 17,431 & 136,181 & 121,423 \\
\hline$E_{\text {Grid }, I}(\mathrm{~W} \mathrm{~h})$ & 7216 & 4636 & 51,584 & 33,133 \\
\hline
\end{tabular}
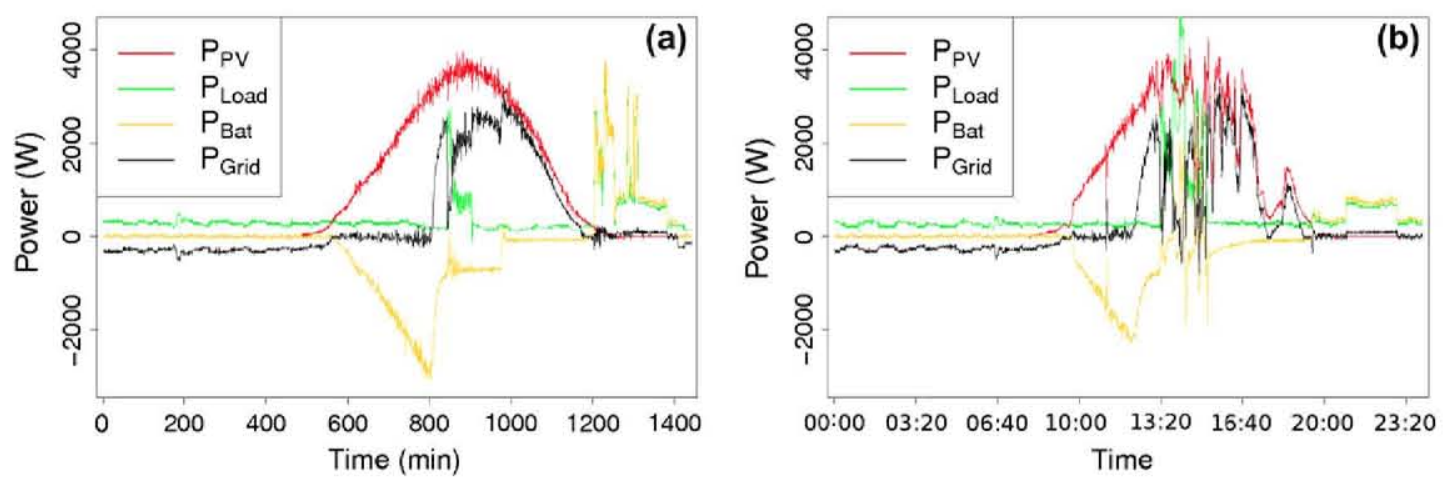

Fig. 7. Electrical energy flows during an example day with $5.4 \mathrm{~kW} \mathrm{~h}$ of battery capacity: (a) without ADSM and (b) with ADSM.

Table 3

Electrical energy flows during the example days and measured weeks with $5.4 \mathrm{~kW}$ h of battery capacity.

\begin{tabular}{|c|c|c|c|c|}
\hline Parameter & $\begin{array}{l}\text { Day without } \\
\text { ADSM }\end{array}$ & $\begin{array}{l}\text { Day with } \\
\text { ADSM }\end{array}$ & $\begin{array}{l}\text { Week without } \\
\text { ADSM }\end{array}$ & $\begin{array}{l}\text { Week with } \\
\text { ADSM }\end{array}$ \\
\hline$E_{P V}(\mathrm{~W} \mathrm{~h})$ & 22,887 & 20,788 & 160,671 & 142,992 \\
\hline$E_{P V, \text { load }}(\mathrm{W} \mathrm{h})$ & 3331 & 5769 & 27,060 & 39,325 \\
\hline$E_{B a t, E}(\mathrm{Wh})$ & 8359 & 5884 & 56,529 & 45,222 \\
\hline$E_{B a t, I}(\mathrm{~W} \mathrm{~h})$ & 4160 & 3163 & 28,417 & 23,138 \\
\hline$E_{\text {Grid,I }}(\mathrm{W} \mathrm{h})$ & 3127 & 2698 & 21,454 & 19,676 \\
\hline$\xi(\%)$ & 70.5 & 77 & 72.1 & 76 \\
\hline
\end{tabular}

sumption for all hours after sunset, but at early morning the house needs to import electricity from the grid. Notice that in this example the weather conditions are not the same, even so the ADSM locates the best hours to run the deferrable loads. Table 3 shows the amount of energy which have taken place in the house during the experiments. The measured week with ADSM has less generated energy than the one without ADSM because of worse weather conditions, even so the ADSM increases the selfconsumption factor in $3.9 \%$ in average.

\section{Final remarks and conclusions}

This article has presented, through simulated and real experiments, the effects of storage and ADSM in a house equipped with PV generation and grid connection. Results have shown the house electrical energy balances in daily and yearly studies, activating and deactivating the ADSM system and modifying the battery capacity. The use of both techniques increases the energy management considerably and allows the implementation of different electric behaviors in order to achieve a specific energy objective. In our case, the energy objective is the self-consumption maximization, reducing the use of the grid and supplying the highest amount of demanded electrical energy from the local sources (PV generation in our system). In order to evaluate it an evaluation methodology has been developed including the definition of the self-consumption factor. Its definition is a evaluation proposal which we have introduced in previous works and refined in this paper. We expect that it will be useful for the evaluation of this kind of facilities in a near future.

We have shown that the relationship between electrical energy flows and the storage capacity is not linear. There is a different variation of theses flows for low capacity levels, achieving a plateau for capacities higher than 2 days of autonomy. The change of this trend takes place with storage capacities close to one day of autonomy. As expected, the relationship between the self-consumption factor and 
the capacity follows a similar evolution than the electrical energy flows. This relationship is an important design criterion, which involves that oversized storage does not produces relevant energy benefits with regard to the local energy optimization. Designers must also take into account the battery float charge consumption trends, which are not normally considered, but as we have seen it is very important for small battery capacities, which will be expected to start arriving at these kinds of facilities.

We have also observed the effects of ADSM. ADSM presents important improvements in the local electricity flows, integrating the generation and the user demand patterns. The effects of ADSM are not constant with the storage capacity, increasing considerably the self-consumption factor for low storage and disappearing for high capacity levels. In any case, this technique reduces the use of the storage systems and therefore reduces the losses with regard to the storage system efficiency. In conclusion, the ADSM performs many advantages, which the main ones are:

- To decrease energy losses: The use of ADSM increases a direct use of the local sources to the detriment of the storage use, reducing the losses with regard to the efficiency. Moreover, the ADSM systems have no physical contact with the energy system and therefore its use does not affect the global system efficiency.

- To reduce the storage size: The same effects produced by a system without ADSM can be obtained with ADSM reducing at the same time the batteries size. It involves that the storage systems sizes can be reduced and therefore it decreases the related costs. Moreover, less waste will be generated when recycling the lead-acid batteries at the end of their useful life and therefore it reduces the environmental impact associated to the storage systems.

- To increase the electricity management possibilities: By actuating on the demand, the number of variables involved in the global energy management increases. In this paper, we have focused this management in the self-consumption maximization. By modifying this target, different energy policies can be carried out depending on the user needs, e.g. the load displacement to lowcost electricity hours or to avoid power consumption over a defined threshold.

- Easy scalability: Because ADSM can be implemented by simple electronics and software controllers, the system size is not an important constriction to this technique. On the other hand, the principal limit of ADSM is the percentage of deferrable loads, which in most cases is difficult to increase.

- User collaboration: The ADSM usually involves the user in the house energy management, by informing him about his consumption and the house energy situation. It makes the user aware of the energy demand and it usually involves the consumption reduction.

In this study we have also responded to the main challenges of the ADSM presented in the introduction for a possible residential implementation. We have developed an ICT infrastructure using the irradiance forecasts from the State Meteorological Agency and the house communication network supported by the electrical appliances. The local control system takes the local conditions information and decides when loads should be placed in order to optimize the self-consumption. The complexity of the system increases, but this may be acceptable if one takes into account the improvements arising from a technically and economically point of view. Also the growth in penetration of smart-metering and domotic equipments for other uses has to be taken into account, thus complexity increase in the system shall be attached in anyway for other reasons.

As a general conclusion, the combination of small-scale storage with Active Demand-Side Management significantly improves the local use of PV, thus increasing the PV value for the user. Self-Consumption serves as an important energy management strategy, reducing the electricity transport and encouraging the user to control his energy behavior. Moreover, the use of these techniques will play an important role in the future smart-grids, helping to guarantee the energy supply and reducing the raw materials imports. On this last point we must mention the further penetration of electric cars, for which the network must be prepared. Using techniques similar to those proposed in this article may be the solution to this problem will be presented in the near future.

\section{Acknowledgments}

M. Castillo is sponsored by the Spanish Ministry of Education with a PhD Grant (FPU-2010). This work has been financed by the Spanish Ministry of Education and Science (Plan Nacional I $+\mathrm{D}+\mathrm{I}$ 204-2007) within the framework of the project Gestión de la Demanda Eléctrica Doméstica con Energía Solar Fotovoltaica (ENE2007-66135). The authors want to thank also the Escuela Técnica Superior de Ingenieros de Telecomunicación of the Technical University of Madrid for their support in the construction and maintenance of "MagicBox" prototype.

\section{References}

Beyea, J., 2010. The smart electricity grid and scientific research. Science 328 (5981), 979-980.

Bhandari, R., Stadler, I., 2009. Grid parity analysis of solar photovoltaic system in germany using experience curves. Solar Energy 83 (9), 1634 1644

Caamaño-Martín, E., Laupkamp, H., Jantsch, M., Erge, T., Thornycroft, J., Moor, H.D., Cobben, S., Suna, D., Gaiddon, B., 2008. Interaction between photovoltaic distributed generation and electricity networks. Progress in Photovoltaics 16 (7), 629-643.

Castillo-Cagigal, M., Gutiérrez, A., Monasterio-Huelin, F., CaamañoMartín, E., Masa-Bote, D., Jiménez-Leube, J., 2011. A semi-distributed electric demand-side management system with PV generation for self-consumption enhancement. Energy Conversion and Management 52 (7), 2659-2666. 
Denholm, P., Margolis, R.M., 2007. Evaluating the limits of solar photovoltaics (PV) in electric power systems utilizing energy storage and other enabling technologies. Energy Policy 35 (9), 4424-4433.

European Commission, 2002. Towards a EU Strategy for the Security of Energy Supply. Tech. Rep. COM (2002) 321, EU.

Foidart, F., Oliver-Solá, J., Gasol, C.M., Gabarrel, X., Rieradevall, J., 2010. How important are current energy mix choices on future sustainability? Case study: Belgium and Spain - projections towards 2020-2030. Energy Policy 38 (9), 5028-5037.

Hadjipaschalis, I., Poullikkas, A., Efthimiou, V., 2009. Overview of current and future energy storage technologies for electric power applications. Renewable and Sustainable Energy Reviews 13 (6-7), 1513-1522.

Koeppel, G., Korpas, M., 2008. Improving the network infeed accuracy of non-dispatchable generators with energy storage devices. Electric Power Systems Research 78 (12), 2024-2036.

Lior, N., 1997. Energy resources and use: the present situation and possible paths to the future. Energy 33 (9), 842-857.

Masa-Bote, D., Caamaño-Martín, E., 2010. Forecast of energy production for pv systems $24 \mathrm{~h}$ ahead. In: 25th European Photovoltaic Solar Energy Conference. WIP-Renewable Energies, Munich, Germany, pp. 4813-4819.

Moura, P.S., de Almeida, A.T., 2010. Multi-objective optimization of a mixed renewable system with demand-side management. Renewable and Sustainable Energy Reviews 14 (5), 1461-1468.

Mulder, G., De Ridder, F., Six, D., 2010. Electricity storage for gridconnected household dwellings with PV panels. Solar Energy 84 (7), 1284-1293.

Nair, N.-K.C., Garimella, N., 2010. Battery energy storage systems: assessment for small-scale renewable energy integration. Energy and Buildings 42 (11), 2124-2130.
Papagiannis, G., Dagoumas, A., Lettas, N., Dokopoulos, P., 2008. Economic and environmental impacts from the implementation of an intelligent demand side management system at the European level. Energy Policy 36 (1), 163-180.

Programe P.P.S., 2010. Trends in Photovoltaics Applications: Survey Report of Selected IEA Countries Between 1992 and 2009. Tech. Rep. IEA-PVPS T1-19:2010. International Energy Agency.

REE, 1998. Proyecto INDEL, Atlas de la Demanda Eléctrica Española. Project Final Report, Madrid, Spain.

Salkind, A.J., Cannone, A.G., Trumbure, F.A., 2001. Lead-acid battery. In: Linden, D., Reddy, T.B. (Eds.), . In: Handbook of Batteries, vol. 23. McGraw-Hill, NY, pp. 586-673.

Spiegel, R.J., Kern, E.C., Greenberg, D.L., 1997. Demostration of the environmental and demand-side management benefits of grid-connected photovoltaic power systems. Solar Energy 62 (5), 345-358.

Strbac, G., 2008. Demand side management: Benefits and challenges. Energy Policy 36 (12), 4419-4426.

Wagner, R., 1997. Large lead/acid batteries for frequency regulation, load levelling and solar power application. Journal of Power Sources 67 (12), $163-172$.

Widén, J., Wckelgard, E., Lund, P.D., 2009. Options for improving the load matching capability of distributed photovoltaics: methodology and application to high-latitude data. Solar Energy 83 (11), 1953-1966.

Wood, G., Newborough, M., 2003. Dynamic energy-consumption indicators for domestic appliances: environment, behaviour and design. Energy and Buildings $35(8), 821-841$. 